\title{
Comparative study between the effect of neural versus intra-articular dextrose prolotherapy on pain and disability in patients with knee osteoarthritis
}

\author{
Rehab A. Sallam*, Aya A. Abdelkhabir and Adel A. Shabana
}

\begin{abstract}
Background: Osteoarthritis $(\mathrm{OA})$ is a degenerative disease which presents with joint pain and stiffness and reduced mobility. Knee OA is the commonest cause of disability in adults. Dextrose prolotherapy is a new option used to treat mild-to-moderate knee OA. Neural prolotherapy (NPT) is multiple small injections under the skin targeting painful areas with natural substances. The aim of work was to evaluate and compare neural prolotherapy versus intra-articular dextrose prolotherapy effect on relieving pain and improving disability of knee OA.

Results: VAS and WOMAC scores improved significantly immediately and at 3 and at 6 months, respectively, in group I compared with group II $(P<0.001)$. The decrease in VAS scores and all the Western Ontario and McMaster Universities Osteoarthritis Index (WOMAC) scores in group I along the follow-up period in comparison with the baseline scores was statistically significant $(P<0.001)$. In group II, only WOMAC pain and stiffness scores improved significantly. ROM showed insignificant increase in both groups at 3 and 6 months assessment. On follow-up, range of motion increased in both groups and reached significance in group I $(P=.002)$.

Conclusion: Dextrose prolotherapy both intra-articular and periarticular (neural) is a very effective and cheap therapy for knee OA with good patient selection. Neural prolotherapy significantly relieves pain and improves function in patients with knee osteoarthritis when compared with intra-articular prolotherapy thus avoiding hazards of intra-articular knee injections.
\end{abstract}

Keywords: Osteoarthritis, Intra-articular dextrose prolotherapy, Neural prolotherapy

\section{Background}

Osteoarthritis (OA) is a degenerative disease which presents with joint pain and stiffness and reduced mobility. Knee OA is the commonest cause of disability in adults, and it usually affects quality of life [1-3]. The origin of pain and disability does not seem to be clear, but there are many pain generators in the ligaments, tendons, articular capsule, periarticular ligaments, synovium, bone, and lateral meniscus that are incriminated in pain [4].

\footnotetext{
* Correspondence: Rehabsallam@hotmail.com

Physical Medicine, Rheumatology and Rehabilitation Department, Mansoura Faculty of Medicine, Mansoura University, Mansoura, Egypt
}

Conventional management of knee OA includes acetaminophen, nonsteroidal anti-inflammatory drugs, glucosamine, chondroitin, opiates, topical capsaicin therapy, intra-articular hyaluronic acid, corticosteroid injections, acupuncture, and use of wedge insoles [5], but none of them completely resolves pain in knee OA [6].

Prolotherapy (proliferation therapy) is an injectionbased treatment used for chronic musculoskeletal conditions. It is an alternative medicinal practice. It includes injection of an irritant substance in joint space, weak ligament, or insertion of tendon to treat pain and stiffness [7-9]. Dextrose prolotherapy is a new option used to treat mild-to-moderate knee OA. It includes injection 
of dextrose inside or outside joint space to enhance healing of tissues with chronic injuries $[10,11]$.

The mode of action of dextrose prolotherapy is not clear. Although some studies have recommended using dextrose prolotherapy in management of pain and improvement of function in patients with knee OA, it needs more studies [12-16].

Neural prolotherapy (NPT) is based on the management of neurogenic inflammation and nerve injury as it consists of multiple small injections immediately under the skin targeting painful areas where the nerves are sensitive with simple and natural substances [17].

\section{Aim of work}

The aim of the study is to evaluate and compare neural prolotherapy versus intra-articular dextrose prolotherapy effect on relieving pain and improving disability scores of knee OA.

\section{Methods}

This is a comparative study that included 80 patients diagnosed as chronic knee osteoarthritis according to ACR criteria [18]. Exclusion criteria included body mass index (BMI) $>45 \mathrm{~kg} / \mathrm{m}^{2}$, obvious ongoing psychiatric illness, patient with skin pathology at site of injection such as infection, wound or malignancy, coagulopathy, diabetes mellitus, intra-articular injection or prolotherapy within the last year, history of trauma within 3 months prior to study, and indication for surgical arthroplasty. The study was approved by the institutional research board (Ethical committee), and a verbal and written consent were taken from the patients. Severity of knee OA was graded according to the Kellgren-Lawrence classification scale for radiological assessment of OA [19]. They were randomly divided into two groups:

\section{Group I}

All analgesics were stopped 2 days before and for 2 weeks after injections. The patients of this group received 8 weekly subcutaneous injections of $0.5-1 \mathrm{ml}$ of buffered dextrose $5 \%$ (by solving $500 \mathrm{ml}$ of dextrose $5 \%$ with $2.4 \mathrm{ml}$ of sodium bicarbonate 8.4) in each CCI (chronic constriction injury) point which is formed by cutaneous nerve swelling proximal to its point of penetration of the fascial layer at the fascial transition zone, along the pathways of superficial nerves around knee and tender points around knee [20, 21] (Fig. 1).

The needle used was $25 \mathrm{G}$ needle, and it was applied to subcutaneous tissue; then we did fanning of that needle (redirected it in a new direction) and repeated this (2-3) times. Two milliliters of the solution were injected in each tender point [22].

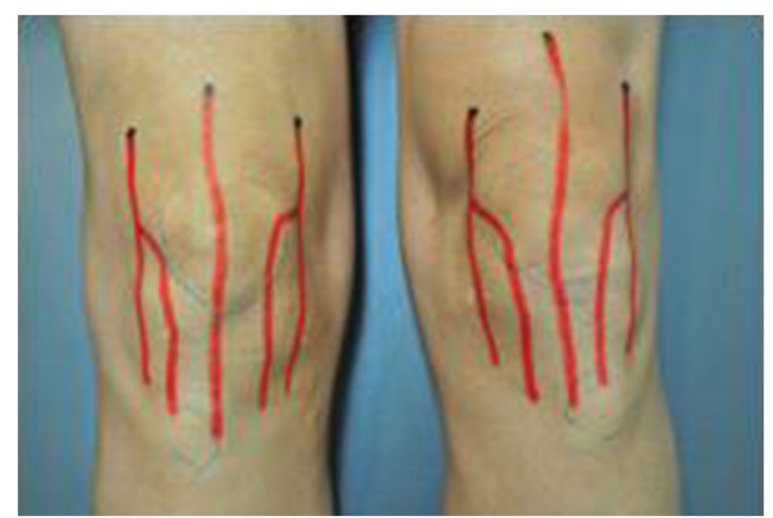

Fig. 1 Anterior femoral nerves \& chronic constriction injury points

\section{Group II: intra-articular group}

All analgesics were stopped 2 days before and for 2 weeks after injections. Eight milliliters of dextrose 10\%, and $2 \mathrm{ml}$ of lidocaine $2 \%$ via a lateral approach using 23G needle were injected into the knee joint. Injection was repeated every 2 weeks for 8 weeks [23]. After injections, we advised the two groups to use ice pack for few minutes at the site of injection twice daily for 2 days. In case of post-injection pain, we gave the patient acetaminophen tablet every $6 \mathrm{~h}$ for 1 day. Patients were asked to rest their knee for 3 days and to do quadriceps strengthening exercises (static exercise) [22].

Follow-up of patients were done at the end of sessions and after 3 and 6 months by the following: the visual analog scale (VAS) for pain [24]; Western Ontario and McMaster Universities Osteoarthritis Index (WOMAC) for assessment of knee pain, stiffness, and physical function [25]; and goniometer for the range of movement (ROM) [23].

\section{Statistical analysis}

All statistical analyses were performed using SPSS for Windows version 20.0 (SPSS, Chicago, IL, USA). All continuous data were normally distributed and were expressed in mean \pm standard deviation (SD), while categorical data were expressed in number and percentage. The comparisons were determined using Student's $t$ test for two variables with continuous data of normal distribution. Chi-square test was used for comparison of variables with categorical data. Repeated measure ANOVA test was used for comparison of the variable along the follow-up period. Statistical significance was set at $P \leq$ 0.05 .

\section{Results}

The mean age of patients in group 1 of neural prolotherapy was $55.5 \pm 7.9$, while the second group of intraarticular prolotherapy was $54 \pm 8.7$. Regarding age, sex, 
duration of disease, BMI, and $\mathrm{x}$-ray score of neural prolotherapy and intra-articular prolotherapy, there was no significant difference between the two groups $(P=0.391$, $0.377,0.565,0.944$, and 0.654 , respectively) (Table 1 ).

Comparing the VAS and WOMAC scores between the two groups revealed a statistically significant improvement in the VAS and WOMAC scores of total pain, stiffness, and function immediately and at 3 and 6 months, respectively, in group I of neural prolotherapy $(P<0.001)$ (Tables 2 and 3$)$.

The decrease in VAS and WOMAC scores (total pain, stiffness, and function) in group I was statistically significant all through the follow-up period in comparison to the baseline $(P<0.001)$. In group II, only WOMAC pain and stiffness scores improved significantly along the same period (as seen in Table 2). As regards knee ROM, it significantly increased only in group I on follow-up ( $P$ $=0.002)$ (Table 4).

\section{Discussion}

Prolotherapy is a regenerative therapy which was discovered in 1950s. The word "prolotherapy" is derived from "proliferation". The substance that is usually used in prolotherapy is hypertonic dextrose $[11,26]$.

The mechanism of action of dextrose prolotherapy is unclear. The most acceptable mechanism of action is that dextrose stimulates the inflammatory pathway. Dextrose increases cytokines and growth factors, which in turn enhances healing of affected tissue and improve joint movement [12].

Dextrose enhances regeneration of the joint cartilage. Many evidence said that prolotherapy stimulates maturation of collagen fibers and fibrous tissue of injured ligaments [27]. Studies stated that dextrose prolotherapy has better effect than local anesthetic injection and exercise [28].

Prolotherapy is used as an alternative therapy in many musculoskeletal diseases. Multiple studies were done on the treatment of knee OA with dextrose prolotherapy that support its healing and regenerating effect [29]. With longer periods of follow-up, dextrose prolotherapy might improve radiographic grade and increase thickness of articular cartilage [30].

Our study illustrated that both intra-articular and periarticular prolotherapies caused a reduction in the total WOMAC score at the end of the 6-month follow-up by 24 points in the periarticular group and 2.7 points in the intraarticular group. Rabago et al. had the same results in which periarticular prolotherapy caused reduction in WOMAC score by 15.32 points at 52 weeks [14]. On the other hand, another study stated that intra-articular prolotherapy caused significant reduction in the WOMAC score by 30.5 points which is not similar to our results [13].

Evaluation of the WOMAC subscale in our study revealed that periarticular dextrose prolotherapy caused its reduction by 6.9 points compared with 0.9 in the intraarticular prolotherapy group. Periarticular injection may have a better effect in alleviating pain as it reduces neurogenic inflammation [31].

The WOMAC stiffness subscale revealed reduction by 1.4 points in the periarticular prolotherapy group versus 0.5 point in the intra-articular prolotherapy group, and WOMAC function subscale showed reduction by 13.7 points in the periarticular prolotherapy group versus 1.4 in the intra-articular prolotherapy group.

One study stated that the intra-articular dextrose prolotherapy group had reduction in the WOMAC pain subscale by 6.8 points, in the WOMAC stiffness subscale by 2.3 points, and in the WOMAC function subscale by 20.8 points [32]. This difference from our results may be due to variable intervals between injections.

The WOMAC score significantly decreased until 3 months, then it maintained during the whole period of the study which means that prolotherapy effect reached a plateau after 3-6 months as shown in other studies [13]. This may be due to the overuse of the knee after a transient reduction of pain and improvement of function and dismissing the recommendations about gradual increase of load on the knee.

Regarding the VAS score, the result agrees with Rezasoltani et al. who showed also more improvement in the

Table 1 Comparison of age, sex, duration of disease, BMI, and x-ray score between neural prolotherapy and intra-articular prolotherapy

\begin{tabular}{|c|c|c|c|c|}
\hline & \multirow{2}{*}{$\begin{array}{l}\text { Neural prolotherapy } \\
\text { Mean } \pm \text { SD }\end{array}$} & \multirow{2}{*}{$\begin{array}{l}\text { Intra-articular prolotherapy } \\
\text { Mean } \pm \text { SD }\end{array}$} & \multicolumn{2}{|l|}{$t$ test } \\
\hline & & & $\bar{T}$ & $P$ \\
\hline Age (years) & $55.5 \pm 7.9$ & $54.0 \pm 8.7$ & 0.863 & 0.391 \\
\hline \multicolumn{5}{|l|}{$\operatorname{Sex}(n, \%)$} \\
\hline Females & $18,45 \%$ & $22,55 \%$ & & \\
\hline Males & $22,55 \%$ & $18,45 \%$ & $0.781^{*}$ & 0.377 \\
\hline Duration of disease (years) & $13.6 \pm 6.6$ & $12.7 \pm 7.5$ & 0.578 & 0.565 \\
\hline BMI $\left(\mathrm{kg} / \mathrm{m}^{2}\right)$ & $32.4 \pm 4.7$ & $32.3 \pm 4.0$ & 0.071 & 0.944 \\
\hline Kellgren-Lawrence score & $2.8 \pm 0.8$ & $2.7 \pm 0.7$ & 0.449 & 0.654 \\
\hline
\end{tabular}

${ }^{*} \mathrm{X}^{2}$ value, chi square test 
Table 2 Comparison of VAS scores between neural prolotherapy and intra-articular prolotherapy

\begin{tabular}{|c|c|c|c|c|}
\hline & Neural prolotherapy & Intra-articular prolotherapy & $t$ test & \\
\hline & Mean \pm SD & Mean \pm SD & $T$ & $P$ \\
\hline At baseline & $7.2 \pm 1.0$ & $7.1 \pm 1.1$ & 0.106 & 0.916 \\
\hline Immediate & $2.9 \pm 1.4$ & $6.1 \pm 1.2$ & 11.048 & $<0.001$ \\
\hline At 3 months & $3.0 \pm 1.1$ & $6.5 \pm 1.4$ & 11.344 & $<0.001$ \\
\hline At 6 months & $3.6 \pm 1.3$ & $6.9 \pm 1.3$ & 10.889 & $<0.001$ \\
\hline \multicolumn{5}{|c|}{ Repeated measure ANOVA test } \\
\hline F & 101.091 & 4.334 & & \\
\hline$P$ & $<0.001$ & 0.006 & & \\
\hline
\end{tabular}

Table 3 Comparison of total WOMAC score between neural prolotherapy and intra-articular prolotherapy

\begin{tabular}{|c|c|c|c|c|}
\hline & \multirow{2}{*}{$\begin{array}{l}\text { Neural prolotherapy } \\
\text { Mean } \pm \text { SD }\end{array}$} & \multirow{2}{*}{$\begin{array}{l}\text { Intra-articular prolotherapy } \\
\text { Mean } \pm \text { SD }\end{array}$} & \multicolumn{2}{|l|}{$t$ test } \\
\hline & & & $\bar{T}$ & $P$ \\
\hline \multicolumn{5}{|c|}{ Total WOMAC score } \\
\hline At baseline & $63.8 \pm 8.2$ & $61.2 \pm 7.3$ & 1.522 & 0.132 \\
\hline Immediate & $36.8 \pm 10.3$ & $55.5 \pm 8.0$ & 9.158 & $<0.001$ \\
\hline At 3 months & $37.5 \pm 10.6$ & $57.2 \pm 8.8$ & 9.199 & $<0.001$ \\
\hline At 6 months & $39.8 \pm 10.5$ & $58.5 \pm 8.3$ & 8.919 & $<0.001$ \\
\hline \multicolumn{5}{|c|}{ Repeated measure ANOVA test } \\
\hline F & 69.787 & 3.262 & & \\
\hline$P$ & $<0.001$ & 0.023 & & \\
\hline \multicolumn{5}{|c|}{ WOMAC pain score } \\
\hline At baseline & $14.5 \pm 2.0$ & $14.6 \pm 1.7$ & 0.181 & 0.857 \\
\hline Immediate & $6.5 \pm 1.3$ & $12.6 \pm 2.3$ & 14.984 & $<0.001$ \\
\hline At 3 months & $6.9 \pm 1.5$ & $13.2 \pm 2.3$ & 15.001 & $<0.001$ \\
\hline At 6 months & $7.6 \pm 1.7$ & $13.7 \pm 2.2$ & 13.715 & $<0.001$ \\
\hline \multicolumn{5}{|c|}{ Repeated measure ANOVA test } \\
\hline$F$ & 218.784 & 6.066 & & \\
\hline$P$ & $<0.001$ & $<0.001$ & & \\
\hline \multicolumn{5}{|c|}{ WOMAC stiffness score } \\
\hline At baseline & $4.1 \pm 1.2$ & $4.2 \pm 1.1$ & 0.197 & 0.845 \\
\hline Immediate & $1.6 \pm 0.8$ & $3.1 \pm 1.1$ & 6.951 & $<0.001$ \\
\hline At 3 months & $1.8 \pm 1.0$ & $3.5 \pm 1.2$ & 7.004 & $<0.001$ \\
\hline At 6 months & $2.7 \pm 1.1$ & $3.7 \pm 1.1$ & 4.211 & $<0.001$ \\
\hline \multicolumn{5}{|c|}{ Repeated measure ANOVA test } \\
\hline$F$ & 49.956 & 6.948 & & \\
\hline$P$ & $<0.001$ & $<0.001$ & & \\
\hline \multicolumn{5}{|c|}{ WOMAC function score } \\
\hline At baseline & $43.0 \pm 5.9$ & $42.4 \pm 4.9$ & 1.341 & 0.184 \\
\hline Immediate & $28.7 \pm 8.6$ & $39.8 \pm 5.4$ & 7.027 & $<0.001$ \\
\hline At 3 month & $28.8 \pm 8.8$ & $40.4 \pm 5.8$ & 7.065 & $<0.001$ \\
\hline At 6 months & $29.6 \pm 8.9$ & $41.0 \pm 5.4$ & 6.988 & $<0.001$ \\
\hline \multicolumn{5}{|c|}{ Repeated measure ANOVA test } \\
\hline F & 34.638 & 1.510 & & \\
\hline$P$ & $<0.001$ & 0.214 & & \\
\hline
\end{tabular}


Table 4 Comparison of ROM between the neural prolotherapy and the Intra-articular prolotherapy

\begin{tabular}{lllll}
\hline & Neural prolotherapy & IA prolotherapy & \multicolumn{2}{l}{$\boldsymbol{t}$ test } \\
\cline { 4 - 5 } & Mean \pm SD & Mean \pm SD & $\boldsymbol{T}$ & $\boldsymbol{P}$ \\
\hline At baseline & $103.9 \pm 5.9$ & $105.1 \pm 6.3$ & 0.938 & 0.351 \\
Immediate & $109.1 \pm 7.1$ & $107.4 \pm 7.1$ & 1.089 & 0.279 \\
At 3 months & $108.5 \pm 7.3$ & $107.1 \pm 6.9$ & 0.898 & 0.372 \\
At 6 months & $106.9 \pm 6.9$ & $106.7 \pm 6.9$ & 0.988 & 0.326 \\
Repeated measure ANOVA test & & & \\
$F$ & 5.072 & 0.795 & & \\
$P$ & 0.002 & 0.498 & & \\
\hline
\end{tabular}

VAS score in the periarticular group more than the intra-articular group [23] and disagrees with Sit et al. who showed nonsignificant difference in both groups in pain relief evaluated by the VAS score [33]. This may be due to the variation of pain perception between populations and follow-up periods.

Some studies, like our study showed that improvement decreased over time, and occasionally symptoms increased again after months, which denotes short-term effect of this therapy [6]. Although, pain recurs gradually after several months of treatment, but it is not as severe as it was before treatment; this may suggest that those patients should have multiple injections at intervals to keep the desired effect.

In our study, patients showed improvement of ROM in the neural prolotherapy group and no improvement in the intra-articular prolotherapy group; however, the difference between these groups was insignificant at follow-up. Unlike our study, Eslamianm and Amouzandeh showed significant improvement in ROM in intra-articular prolotherapy [32].

The potential cause is that other pain sources in the patient including surrounding tendons and ligaments were ignored. In our study, we did not treat fibro-osseous junctions or enteropathy with dextrose injections around those structures. Hence, it seems that ligaments and other structures must be treated first to get the desirable effect of injections. The ligament's integrity and strength have a major role in joint stability, and their dysfunction is an important cause of exacerbation of OA [34].

Limitations of our study include small sample size and short period of follow-up.

\section{Conclusions}

Dextrose prolotherapy both intra-articular and periarticular (neural) is a very effective and cheap therapy for knee OA with good patient selection. Neural prolotherapy significantly relieves pain and improves function in patients with knee osteoarthritis when compared with intra-articular prolotherapy. In addition, neural prolotherapy avoids hazards of intra-articular knee injections.

\section{Abbreviations}

OA: Osteoarthritis; NPT: Neural prolotherapy; CCl: Chronic constriction injury; VAS: Visual analog scale; WOMAC: Western Ontario and McMaster Universities Osteoarthritis Index; ROM: Range of movement; SD: Standard deviation

\section{Acknowledgements \\ Not applicable}

\section{Authors' contributions}

RS contributed in writing the manuscript, doing the statistics, and revising the clinical work. AA did the clinical part of the study. AS did the study design and revised the research work. The authors read and approved the final manuscript.

\section{Funding}

Nil (authors' own fund)

\section{Availability of data and materials}

The datasets used and/or analyzed during the current study are available from the corresponding author on reasonable request.

\section{Declarations}

Ethics approval and consent to participate

Patients were informed about the nature of the study, and a written consent was taken from the participants who agreed to share. The study was approved by the institutional research board of Mansoura Faculty of Medicine (IRB); the code number is MS/17.12.87.

\section{Consent for publication}

Not applicable

Competing interests

The authors declare that they have no competing interests.

Received: 23 May 2021 Accepted: 1 August 2021

Published online: 06 October 2021

\section{References}

1. Yelin E (2003) Cost of musculoskeletal diseases: impact of work disability and functional decline. J Rheumatol Suppl. 68:8-11

2. Helmick CG, Felson DT, Lawrence RC, Gabriel S, Hirsch R, Kwoh CK et al (2008) National Arthritis Data Workgroup. Estimates of the prevalence of arthritis and other rheumatic conditions in the United States. Part II. Arthritis Rheum. 58(1):26-35

3. Lee J, Song J, Hootman JM, Semanik PA, Chang RW, Sharma L, van Horn L, Bathon JM, Eaton CB, Hochberg MC, Jackson R, Kwoh CK, Mysiw WJ, Nevitt M, Dunlop DD (2013) Obesity and other modifiable factors for physical inactivity measured by accelerometer in adults with knee osteoarthritis. Arthritis Care Res (Hoboken). 65(1):53-61. https://doi.org/10.1002/acr.21754

4. Felson DT (2005) The sources of pain in knee osteoarthritis. Curr Opin Rheumatol. 17(5):624-628. https://doi.org/10.1097/01.bor.0000172800.4 9120.97

5. Buckwalter JA, Stanish WD, Rosier RN, Schenck RC Jr, Dennis DA, Coutts RD (2001) The increasing need for nonoperative treatment of patients with osteoarthritis. Clin Orthop Relat Res 385:36-45

6. Samson DJ, Grant MD, Ratko TA, Bonnell CJ, Ziegler KM, Aronson N (2007) Treatment of primary and secondary osteoarthritis of the knee. Evid Rep Technol Assess (Full Rep) (157):1-157

7. Distel LM, Thomas TM (2011) Prolotherapy: a clinical review of its role in treating chronic musculoskeletal pain. PM\&R 3(6):S78-S81

8. Bauer BA (2012) Prolotherapy: solution to low back pain? Mayo Clinic. https://www.mayoclinic.org/prolotherapy/expert-answers/faq-20058347.

9. Rabago D, Nourani B (2017) Prolotherapy for osteoarthritis and tendinopathy: a descriptive review. Curr Rheumatol Rep 19(6):34

10. Linetsky F, Botwin K, Gorfine L, Jay GW, McComb B, Miguel R, et al. Regenerative injection therapy (RIT): effectiveness and appropriate usage. Florida Academy of Pain Medicine (FAPM); 2001. 
11. Rabago D, Mundt M, Zgierska A, Grettie J (2015) Hypertonic dextrose injection (prolotherapy) for knee osteoarthritis: long term outcomes. Complement Ther Med 23(3):388-395

12. Reeves KD, Hassanein K (2000) Randomized prospective double-blind placebo-controlled study of dextrose prolotherapy for knee osteoarthritis with or without ACL laxity. Altern Ther Health Med. 6(2):68-74

13. Rabago D, Zgierska A, Fortney L, Kijowski R, Mundt M, Ryan M, Grettie J, Patterson JJ (2012) Hypertonic dextrose injections (prolotherapy) for knee osteoarthritis: results of a single-arm uncontrolled study with 1-year followup. J Altern Complement Med. 18(4):408-414. https://doi.org/10.1089/acm.2 011.0030

14. Rabago D, Patterson JJ, Mundt M, Kijowski R, Grettie J, Segal NA, Zgierska A (2013) Dextrose prolotherapy for knee osteoarthritis: a randomized controlled trial. Ann Fam Med. 11(3):229-237. https://doi.org/10.1370/afm.1 504

15. Rahimzadeh P, Imani F, Faiz SH, Entezary SR, Nasiri AA, Ziaeefard M (2014) Investigation the efficacy of intra-articular prolotherapy with erythropoietin and dextrose and intra-articular pulsed radiofrequency on pain level reduction and range of motion improvement in primary osteoarthritis of knee. J Res Med Sci. 19(8):696-702

16. Rabago D, Patterson JJ, Mundt M, Zgierska A, Fortney L, Jessica Grettie J et al (2014) Dextrose and morrhuate sodium injections (prolotherapy) for knee osteoarthritis: a prospective open-label trial. J Altern Complement Med. 20(5):383-391. https://doi.org/10.1089/acm.2013.0225

17. Lyftogt J (2013) Perineural injection treatment introductory workshop 9-10

18. Altman R, Asch E, Bloch D, Bole G, Borenestein D, Brandt K et al (1986) Development of criteria for the classification and reporting of osteoarthritis of the knee. Diagnostic and Therapeutic Criteria Committee of the American Rheumatism association. Arthritis Rheum 29(8):1039-1049. https:// doi.org/10.1002/art.1780290816

19. Kellgren JH, Lawrence JS (1957) Radiological assessment of osteo-arthrosis. Ann Rheum Dis. 16(4):494-502. https://doi.org/10.1136/ard.16.4.494

20. Thor JA, Hanapi NM, Halil H, Suhaimi A (2017) Perineural injection therapy in the management of complex regional pain syndrome: a sweet solution to pain. Pain Med 18(10):2041-2045. https://doi.org/10.1093/pm/pnx063

21. Abu Zaid M, Tabra S, Elmorsy S (2018) Effect of perineural injection therapy in moderate and severe knee osteoarthritis; a comparative study. Ann Rheum Dis 77(2):862-863

22. Farpour H, Fereydooni F (2017) Comparative effectiveness of intra-articular prolotherapy versus peri-articular prolotherapy on pain reduction and improving function in patients with knee osteoarthritis: a randomized clinical trial. Electron Physician 9(11):5663-5669. https://doi.org/10.19082/ 5663

23. Rezasoltani Z, Taheri M, Mofrad MK, Mohajerani SA (2017) Periarticular dextrose prolotherapy instead of intra-articular injection for pain and functional improvement in knee osteoarthritis. J Pain Res. 17(10):1179-1187

24. Duncan GH, Bushnell MC, Lavigne GJ (1989) Comparison of verbal and visual analogue scales for measuring the intensity and unpleasantness of experimental pain. Pain. 37(3):295-303. https://doi.org/10.1016/0304-3 959(89)90194-2

25. American College of Rheumatology. Western Ontario and McMaster Universities Osteoarthritis Index (WOMAC) http://www.rheumatology.org/ practice/clinical/clinicianresearchers/outcomes-instrumentation/WOMAC.asp. (Accessed 12 July 2013).

26. Slattengren AH, Christensen T, Prasad S, Jones K (2014) PURLs: prolotherapy: a nontraditional approach to knee osteoarthritis. J Fam Pract. 63(4):206-208

27. Dagenais S, Ogunseitan O, Haldeman S, Wooley JR, Newcomb RL (2006) Side effects and adverse events related to intraligamentous injection of sclerosing solutions (prolotherapy) for back and neck pain: a survey of practitioners. Arch Phys Med Rehabil. 87(7):909-913. https://doi.org/10.1016/ j.apmr.2006.03.017

28. Hung CY, Hsiao MY, Chang KV, Han D, Wang T (2016) Comparative effectiveness of dextrose prolotherapy versus control injections and exercise in the management of osteoarthritis pain: a systematic review and metaanalysis. J Pain Res. 9:847-857. https://doi.org/10.2147/JPR.S118669

29. Soliman D, Sherif N, Omar O, El Zohiery AK (2016) Healing effects of prolotherapy in treatment of knee osteoarthritis healing effects of prolotherapy in treatment of knee osteoarthritis. Egypt Rheumatol Rehabil. 43(2):47-52. https://doi.org/10.4103/1110-161X.181858
30. Fullerton BD (2008) High-resolution ultrasound and magnetic resonance imaging to document tissue repair after prolotherapy: a report of 3 cases. Arch Phys Med Rehabil. 89(2):377-385. https://doi.org/10.1016/j.apmr.2007. 09.017

31. Lyftogt J (2008) Prolotherapy for recalcitrant lumbago. Aus Musculoskeletal Med J. 13:18-20

32. Eslamianm F, Amouzandeh B (2015) Therapeutic effects of prolotherapy with intra-articular dextrose injection in patients with moderate knee osteoarthritis: a single-arm study with 6 months follow up. Ther Adv Musculoskelet Dis 7(2):35-44. https://doi.org/10.1177/1759720X14566618

33. Sit RW, Chung VC, Reeves KD et al (2016) Hypertonic dextrose injections (prolotherapy) in the treatment of symptomatic knee osteoarthritis: a systematic review and meta-analysis. Sci Rep. 6(1):25247. https://doi.org/10.1 038/srep25247

34. Reeves K, Hassanein K (2003) Long-term effects of dextrose prolotherapy for anterior cruciate ligament laxity. Altern Ther Health Med 9:58-62

\section{Publisher's Note}

Springer Nature remains neutral with regard to jurisdictional claims in published maps and institutional affiliations.

\section{Submit your manuscript to a SpringerOpen ${ }^{\circ}$ journal and benefit from:}

- Convenient online submission

- Rigorous peer review

- Open access: articles freely available online

High visibility within the field

- Retaining the copyright to your article

Submit your next manuscript at $\boldsymbol{\nabla}$ springeropen.com 